\title{
Testing the short- and long-term effects of elevated prenatal exposure to different forms of thyroid hormones
}

\author{
Tom Sarraude ${ }^{\text {Corresp., }, 2, \text {, Bin-Yan Hsu }}{ }^{1}$, Ton Groothuis ${ }^{2}$, Suvi Ruuskanen ${ }^{1}$ \\ ${ }^{1}$ Department of Biology, University of Turku, Turku, Finland \\ ${ }^{2}$ Groningen Institute for Evolutionary Life Sciences, University of Groningen, Groningen, Netherlands \\ Corresponding Author: Tom Sarraude \\ Email address: t.sarraude@rug.nl
}

Maternal thyroid hormones (THs) are known to be crucial in embryonic development in humans, but their influence on other, especially wild, animals remains poorly understood. So far, the studies that experimentally investigated the consequences of maternal THs focused on short-term effects, while early organisational effects with long-term consequences, as shown for other prenatal hormones, could also be expected. In this study, we aimed at investigating both the short- and long-term effects of prenatal THs in a bird species, the Japanese quail Coturnix japonica. We experimentally elevated yolk TH content (the prohormone $T_{4}$, and its active metabolite $T_{3}$, as well as a combination of both hormones). We analysed hatching success, embryonic development, offspring growth and oxidative stress as well as their potential organisational effects on reproduction, moult, and oxidative stress in adulthood. We found that eggs injected with $\mathrm{T}_{4}$ had a higher hatching success compared with control eggs, suggesting conversion of $T_{4}$ into $T_{3}$ by the embryo. We detected no evidence for other short-term or long-term effects of yolk THs. These results suggest that yolk thyroid hormones are important in the embryonic stage of precocial birds, but other short- and long-term consequences remain unclear. Research on maternal thyroid hormones will greatly benefit from studies investigating how embryos use and respond to this maternal signalling. Long-term studies on prenatal THs in other taxa in the wild are needed for a better understanding of this hormone-mediated maternal pathway. 
1 Testing the short- and long-term effects of elevated prenatal exposure to different forms of

\section{2 thyroid hormones}

3

8 Groningen, the Netherlands

11 Keywords: maternal hormones; thyroid hormones; avian growth; hatching success; Japanese 12 quails; life-history strategies. 


\section{Abstract}

14 Maternal thyroid hormones (THs) are known to be crucial in embryonic development in humans,

15 but their influence on other, especially wild, animals remains poorly understood. So far, the

16 studies that experimentally investigated the consequences of maternal THs focused on short-term

17 effects, while early organisational effects with long-term consequences, as shown for other

18 prenatal hormones, could also be expected. In this study, we aimed at investigating both the

19 short- and long-term effects of prenatal THs in a bird species, the Japanese quail Coturnix

20 japonica. We experimentally elevated yolk $\mathrm{TH}$ content (the prohormone $\mathrm{T}_{4}$, and its active

21 metabolite $\mathrm{T}_{3}$, as well as a combination of both hormones). We analysed hatching success,

22 embryonic development, offspring growth and oxidative stress as well as their potential

23 organisational effects on reproduction, moult, and oxidative stress in adulthood. We found that

24 eggs injected with $\mathrm{T}_{4}$ had a higher hatching success compared with control eggs, suggesting

25 conversion of $\mathrm{T}_{4}$ into $\mathrm{T}_{3}$ by the embryo. We detected no evidence for other short-term or long-

26 term effects of yolk THs. These results suggest that yolk thyroid hormones are important in the

27 embryonic stage of precocial birds, but other short- and long-term consequences remain unclear.

28 Research on maternal thyroid hormones will greatly benefit from studies investigating how

29 embryos use and respond to this maternal signalling. Long-term studies on prenatal THs in other

30 taxa in the wild are needed for a better understanding of this hormone-mediated maternal

31 pathway. 


\section{Introduction}

33 Maternal effects represent all the non-genetic influences of a mother on her offspring and have

34 received increasing attention in evolutionary and behavioural ecology. Through maternal effects,

35 mothers can influence the fitness of their progeny by adapting their phenotype to expected

36 environmental conditions ("adaptive maternal effects" in Marshall and Uller, 2007; Mousseau

37 and Fox, 1998), and this view is now also incorporated in the human disease literature

38 (Gluckman, Hanson \& Spencer, 2005). Maternal hormones transferred to the offspring can

39 mediate important maternal effects. Historically, research on maternal hormones has mostly

40 focused on steroid hormones (Groothuis et al., 2005; von Engelhardt \& Groothuis, 2011). While

41 research on maternal thyroid hormones has emerged between the $80 \mathrm{~s}$ and the $90 \mathrm{~s}$ in several taxa

42 (mammals, Morreale De Escobar et al., 1985; fish, Brown et al., 1988; birds, Wilson \& McNabb,

43 1997), these hormones are still underrepresented in the literature on hormone-mediated maternal

44 effects (reviewed in Ruuskanen \& Hsu, 2018).

45 Thyroid hormones (THs) are metabolic hormones produced by the thyroid gland and are

46 present in two main forms: the prohormone thyroxine $\left(\mathrm{T}_{4}\right)$ and the biologically active form

47 triiodothyronine $\left(\mathrm{T}_{3}\right)$. THs play a crucial role in various aspects of an individual's life, e.g.

48 development, metabolism and reproduction, across vertebrates, including humans (Morreale de

49 Escobar, Obregon \& Escobar del Rey, 2004; Krassas, Poppe \& Glinoer, 2010). In humans,

50 physiological variation of maternal THs (i.e. no clinical symptoms in both mothers and foetuses)

51 is found to be associated with infant birth weight and IQ in older children (Medici et al., 2013;

52 Korevaar et al., 2016). In other vertebrates, THs in general play a role in brain development and

53 neuronal turnover (mammals, Morreale de Escobar, Obregon \& Escobar del Rey, 2004; birds,

$54 \mathrm{McNabb}, 2007)$. THs control the endothermic heat production, and are therefore important in 
55 thermoregulation in homeothermic species (mammals, Danforth \& Burger, 1984; birds, McNabb 56 \& Darras, 2015).

THs can act, in concert with other hormonal axes, as mediators of life stage transitions

58

across vertebrates (reviewed in Watanabe et al., 2016). The interaction between thyroid hormones and corticosteroids on amphibian metamorphosis is a well-known example of such effect on life stage transition (Kikuyama et al., 1993; Wada, 2008). THs are involved in gonadal development, and hyperthyroidism tends to accelerate maturation (Holsberger \& Cooke, 2005), and coordinate the transition between reproduction and moult (McNabb and Darras, 2015). Administration of exogenous THs is known to stop egg laying and induce moult in birds (Sekimoto et al., 1987; Keshavarz \& Quimby, 2002). THs are also involved in photoperiodic control in seasonal breeding (Dardente, Hazlerigg \& Ebling, 2014). For example, thyroidectomised starlings transferred to long photoperiods became insensitive to future changes in photoperiod, and short photoperiod did not induce gonadal regression (Dawson, 1993). While there has been recent research effort on the influence of maternal THs on offspring traits across vertebrate taxa, there are still substantial gaps in our knowledge. Manipulating yolk hormones within the natural range of a species is necessary to better understand the role of maternal THs in an eco-evolutionary context. In humans, studies have essentially looked at the consequences of clinical hyper- or hypothyroidism (but see Medici et al., 2013). Research in fish has applied supra-physiological doses for aquaculture purposes (Brown et al., 2014). However, these studies do not give information on how variations within the natural range of the species would shape offspring phenotype and affect its fitness, in turn influencing evolution. While recent literature on birds has shown that even physiological variations of prenatal THs can have phenotypic consequences (Ruuskanen et al., 2016; Hsu et al., 2017, 2019; Sarraude et al., 2020), 
78 this view is still underrepresented in maternal THs research.

79 Besides, research on maternal thyroid hormones up to date has mainly investigated the

80 short-term effects of prenatal THs on developing fish (Brown et al., 1988; Raine et al., 2004) and

81 amphibians (Duarte-Guterman et al., 2010; Fini et al., 2012) and pre-fledging birds (Ruuskanen

82 et al., 2016; Hsu et al., 2017, 2019; Sarraude et al., 2020). So far, only a study on rock pigeons

83 has looked at the influence of yolk THs on post-fledging survival and found no effect (Hsu et al.,

84 2017). None of these studies in any taxa investigated the potential organisational effects of

85 prenatal THs on life-history stage transitions in adult life. Early exposure to elevated THs may

86 affect the hypothalamic-pituitary-thyroid (HPT) axis (humans and mice: Alonso et al., 2007;

87 Srichomkwun et al., 2017; Anselmo et al., 2019), via epigenetic modifications for example, such

88 as those induced by adverse early life conditions (Jimeno et al., 2019) or yolk testosterone

89 (Bentz, Becker \& Navara, 2016).

90 Oviparous species, such as birds, are suitable models for studying the role of maternal

91 hormones on the progeny because embryos develop in eggs outside mothers' body. The content

92 of an egg cannot be adjusted by the mother after laying, which facilitates the quantification of

93 hormones transmitted by the mothers. In addition, the measurement and experimental

94 manipulation of maternal hormones in the egg after it has been laid is not confounded by

95 maternal physiology. These advantages combined with their well-known ecology and evolution,

96 birds have become the most extensively studied taxa in research on the function of maternal

97 hormones (Groothuis et al. 2019).

98 Previous studies on prenatal THs in birds focused only on altricial species (great tits,

99 Ruuskanen et al., 2016; rock pigeons, Hsu et al., 2017; collared flycatchers, Hsu et al., 2019,

100 pied flycatchers, Sarraude et al., 2020). Embryonic development differs substantially between 
101 altricial and precocial species. In the latter, embryonic development is more advanced than in the

102 former. In addition, precocial embryos start their endogenous production of TH around mid-

103 incubation, considerably earlier than their altricial counterparts, in which endogenous TH

104 production begins only after hatching (McNabb, Scanes \& Zeman, 1998). While embryonic

105 hormone production may limit the influence of maternal hormones, prenatal hormones have been

106 shown to affect chick endogenous production and sensitivity (Pfannkuche et al., 2011). Overall,

107 exposure to maternal hormones may be of different importance in these two developmental

108 modes.

109 Previous research has studied the effects of $\mathrm{T}_{3}$ only (Raine et al., 2004; Walpita et al.,

110 2007; Fini et al., 2012) or a combination of $\mathrm{T}_{3}$ and $\mathrm{T}_{4}$ (Ruuskanen et al., 2016; Hsu et al., 2017,

111 2019; Sarraude et al., 2020), where the effects of the two forms cannot be separated. Although $\mathrm{T}_{3}$

112 is the biologically active form that binds to the receptors, both $T_{3}$ and $T_{4}$ are deposited in eggs

113 (Prati et al., 1992) and $\mathrm{T}_{4}$ may be converted to $\mathrm{T}_{3}$ via deiodinases from the mother or the

114 developing embryo (Van Herck et al., 2015) or may still exert non-genomic actions (reviewed in

115 Davis et al., 2016). Manipulating yolk $\mathrm{T}_{4}$ and $\mathrm{T}_{3}$ independently would help understanding the

116 relative contribution of these two hormones.

117 In this study, we aimed at assessing the effects of maternal THs on development and life-

118 history traits in a precocial bird species, the Japanese quail (Coturnix japonica). We manipulated

119 eggs with either an injection of $\mathrm{T}_{4}$ or $\mathrm{T}_{3}$ separately, a combination of both hormones, or a control

120 injection of the vehicle saline solution. First, we hypothesise that elevation of yolk THs in

121 Japanese quails positively affects hatching success, as found in two studies on collared

122 flycatchers and rock pigeons (Hsu et al., 2017; Hsu et al., 2019, but see Ruuskanen et al., 2016

123 and Sarraude et al., 2020). Second, elevation of yolk THs is predicted to increase the proportion 
124 of well-developed embryos before hatching, as found in rock pigeons (Hsu et al., 2017). We

125 therefore looked at the age at mortality in unhatched eggs. Third, we expect elevated yolk THs to

126 affect chick growth (in body mass, tarsus and wing length) either positively (Wilson \& McNabb,

127 1997; Hsu et al., 2019; weak effect in Sarraude et al., 2020), negatively (Hsu et al., 2017), or in a

128 sex-specific manner (Ruuskanen et al., 2016). Prenatal THs may exert most of their effects in the

129 offspring early life; this is why we separately tested both posthatch morphological traits and the

130 growth curve. Similarly, we also independently analysed morphological traits at adulthood, as

131 these traits may affect the fitness of an individual. For example, small adult females may lay

132 smaller eggs and larger males may be more dominant. Fourth, we predict that yolk THs will have

133 organisational effects on life-history stage transitions; that is, age at sexual maturity and male

134 gonadal regression (using cloacal gland size as a proxy), and moult when birds are exposed to

135 short photoperiod. Based on the literature mentioned above we expect elevated yolk THs to

136 advance the timing of puberty, gonadal regression and moult. The rate of moult should also be

137 influenced, with birds receiving experimental TH elevation moulting faster. Previous studies

138 have reported that gravid female three-spined sticklebacks (Gasterosteus aculeatus) exposed to

139 predatory cues produced eggs with higher corticosterone (Giesing et al., 2011), disturbed

140 embryonic transcriptome (Mommer \& Bell, 2014), offspring with altered anti-predator behaviour

141 (Giesing et al., 2011) and modified cortisol response in adulthood (Mommer \& Bell, 2013). We

142 may therefore expect elevated yolk THs to similarly induce long-term behavioural changes in

143 response to environmental cues (i.e. photoperiod), via organising effects during the embryonic

144 development. We also explored the effects of yolk THs on reproductive investment in females,

145 another important fitness aspect. Finally, yolk THs may increase oxidative stress due to their

146 stimulating effects on metabolism. 


\section{Material and Methods}

\section{Overview of the method}

149 Japanese quails are easy to maintain in captivity, and their short generation time makes it a good

150 model to investigate the long-term effects of maternal hormones. Rearing birds in captivity

151 allowed us to apply a powerful within-female experimental design (i.e. knowing which chick

152 hatched from which egg which is not feasible in field studies), thus reducing the effect of random

153 variation among females. Moreover, studying the role of natural variation of prenatal THs in

154 precocial species may give additional information to previous studies in altricial species. Finally,

155 Japanese quail is a commonly used model in maternal hormone research with substantial

156 literature available (e.g. McNabb, Blackman \& Cherry, 1985; McNabb, Dicken \& Cherry, 1985;

157 Wilson \& McNabb, 1997; Okuliarova et al., 2011).

158 We injected unincubated eggs from Japanese quails maintained in captivity with either $\mathrm{T}_{4}$

159 or $\mathrm{T}_{3}$ alone, a combination of both hormones, or a saline (control) solution. This design allowed

160 us to explore the effects of $\mathrm{T}_{4}$ and $\mathrm{T}_{3}$ separately, which has not been done in previous studies.

161 The elevation in yolk THs remained within the natural range of this species, a crucial condition

162 to obtain relevant results for an eco-evolutionary context. We measured traits known to be

163 influenced by circulating and yolk THs: hatching success, age at embryonic mortality, growth,

164 transition between life-history stages (i.e., reproductive state and moult) and oxidative stress.

\section{Parental generation and egg collection}

166 The parental generation was composed of adult Japanese quails provided by Finnish

167 private local breeders that were kept in two acclimated rooms. Twenty-four breeding pairs were

168 formed by pairing birds from different breeders. Individuals were identified using metal leg 
169 bands. The floor was covered with $3-5 \mathrm{~cm}$ sawdust bedding. A hiding place, sand and calcium

170 grit were provided. Each pair was housed in indoor aviary dividing into pens of $1 \mathrm{~m}^{2}$ floor area.

171 The temperature was set to $20^{\circ} \mathrm{C}$ with a $16 \mathrm{~L}: 8 \mathrm{D}$ photoperiod (light from 06.00 to 22.00 ). Food

172 (Poultry complete feed, "Kanan Paras Täysrehu”, Hankkija, Finland) was provided ad libitum

173 and water was changed every day.

174 Pairs were monitored every morning to collect eggs for 7 days. Eggs were individually

175 marked (non-toxic marker), weighed and stored in a climate-controlled chamber at $15^{\circ} \mathrm{C}$ and

$17650 \%$ relative humidity. On the last day of collection, a total of 4 to 8 eggs per pair were injected

177 with a solution (see next section).

\section{Preparation of the solution, injection procedure and incubation}

179 The preparation of hormone solution and the procedure of injection were based on previous

180 studies (Ruuskanen et al., 2016; Hsu et al., 2017). In brief, crystal T 4 (L-thyroxine, $\geq 98 \%$

181 HPCL, CAS number 51-48-9, Sigma-Aldrich) and $\mathrm{T}_{3}$ (3,3',5-triiodo-L-thyronine, > 95\% HPCL,

182 CAS number 6893-02-3, Sigma-Aldrich) were first dissolved in $0.1 \mathrm{M} \mathrm{NaOH}$ and then diluted in

$183 \quad 0.9 \% \mathrm{NaCl}$. The injection of thyroid hormones resulted in an increase of two standard deviations

$184\left(\mathrm{~T}_{4}=8.9 \mathrm{ng} / \mathrm{egg}\right.$, equivalent to $1.79 \mathrm{pg} / \mathrm{mg}$ yolk; $\mathrm{T}_{3}=4.7 \mathrm{ng} / \mathrm{egg}$, equivalent to $1.24 \mathrm{pg} / \mathrm{mg}$ yolk$)$,

185 a recommended procedure for hormone manipulation within the natural range (Ruuskanen et al.,

186 2016; Hsu et al., 2017; Podmokła, Drobniak \& Rutkowska, 2018). The control solution (CO)

187 was a saline solution $(0.9 \% \mathrm{NaCl})$. The concentrations of the hormone solutions were based on

188 previous measurements of 15 eggs from the same flock (content per egg (SD) $\mathrm{T}_{4}=15.3(4.4) \mathrm{ng}$,

$189 \mathrm{~T}_{3}=7.6(2.3) \mathrm{ng} ;$ concentrations $(\mathrm{SD}), \mathrm{T}_{4}=4.20(0.89) \mathrm{pg} / \mathrm{mg}$ yolk, $\mathrm{T}_{3}=2.10(0.62) \mathrm{pg} / \mathrm{mg}$

190 yolk).

191 Hormone injections were performed at room temperature in a laminar hood. Eggs were 
192 put sideways, allowing yolks to float up to the middle position. Before injection, the shell was

193 disinfected with a cotton pad dipped in 70\% EtOH. We used a 27G needle (BD Microlance ${ }^{\mathrm{TM}}$ )

194 to pierce the eggshell and then used a $0.3 \mathrm{ml}$ syringe to deliver $50 \mu 1$ of the respective hormone

195 solution or control. After injection, the hole was sealed with a sterile plaster (OPSITE Flexigrid,

196 Smith\&Nephew).

197 In total, 158 eggs were injected and divided as follows over the treatments: $T_{3}$ treatment

$198(\mathrm{~N}=39) ; \mathrm{T}_{4}$ treatment $(\mathrm{N}=39) ; \mathrm{T}_{3}+\mathrm{T}_{4}$ treatment $(\mathrm{N}=40)$; and control, $\mathrm{CO}(\mathrm{N}=40)$. To balance

199 the genetic background of the parents and the effect of storage, each egg laid by the same female

200 was sequentially assigned to a different treatment and the order of treatments was rotated among

201 females. After injection, eggs were placed in an incubator at $37.8^{\circ} \mathrm{C}$ and $55 \%$ relative humidity.

202 Until day 14 after starting incubation, eggs were automatically tilted every hour by $90^{\circ}$. On day

203 14, tilting was halted and each egg was transferred to an individual container to monitor which

204 chick hatched from which egg. On day 16 after injection, (normal incubation time $=17$ days), the

205 temperature was set to $37.5^{\circ} \mathrm{C}$ and the relative humidity to $70 \%$. Eggs were checked for hatching

206 every 4 hours from day 16 onwards. Four days after the first egg hatched, all unhatched eggs

207 were stored in a freezer and dissected to determine the presence of an embryo. The age of

208 developed embryos was assessed according to Ainsworth et al. (2010).

\section{Rearing conditions of the experimental birds}

210 In total, 66 chicks hatched $\left(\mathrm{N}=10 \mathrm{CO}, 15 \mathrm{~T}_{3}, 20 \mathrm{~T}_{4}\right.$ and $\left.21 \mathrm{~T}_{3} \mathrm{~T}_{4}\right)$, yielding a rather low

211 overall hatching success (ca. 40\%). Among the unhatched eggs, 33.7\% (31 out of 92) had no

212 developed embryos, and these were evenly distributed between the treatments $\left(\mathrm{CO}=9 / 40, \mathrm{~T}_{3}=\right.$

$2138 / 39, \mathrm{~T}_{3} \mathrm{~T}_{4}=8 / 40$, and $\mathrm{T}_{4}=6 / 39$ eggs). Discarding the unfertilised eggs gives an overall hatching

214 success of ca. 51\%. Previous studies on Japanese quails have reported comparable hatching 
215 success, even in unmanipulated eggs (e.g. 40\% in Okuliarová, Škrobánek \& Zeman, 2007; ca.

216 60\% in Pick et al., 2016 and in Stier, Metcalfe \& Monaghan, 2019). In addition, the injection

217 procedure itself is also known to reduce hatching success to some extent (Groothuis \& von

218 Engelhardt, 2005). Twelve hours after hatching, the chicks were marked by a unique

219 combination of coloured rings and nail coding and transferred to two cages of $1 \mathrm{~m}^{2}$ floor area and

220 ca. $30 \mathrm{~cm}$ height (ca. 30 chicks/cage, sex and treatments mixed together). The chicks were

221 provided with heating mats and lamps as extra heat sources for the first two weeks. The chicks

222 were fed with sieved commercial poultry feed ("Punaheltta paras poikanen”, Hankkija, Finland),

223 and provided with Calcium and bathing sand. Two weeks after hatching, the chicks were

224 separated in four $1 \mathrm{~m}^{2}$ cages (ca. $30 \mathrm{~cm}$ high) of about 16 individuals. Around 3 weeks after

225 hatching, coloured rings were replaced by unique metal rings. On week 4 after hatching, birds

226 were transferred to eight pens of $1 \mathrm{~m}^{2}$ floor area (average of 7.1 birds/pen, range $=4-9$ ), under

227 the same conditions as the parents. Around the age of sexual maturity (ca. 6-8 weeks after

228 hatching), the birds were separated by sex in twelve $1 \mathrm{~m}^{2}$ pens (average of $4.8 \mathrm{birds} /$ pen, range $=$

$2294-5$ ). The chicks were under the same photoperiod as the adults (i.e. 16L:8D).

\section{Monitoring of growth and reproductive maturation}

231 Body mass and wing length were measured twelve hours after hatching. Tarsus was not

232 measured because it bends easily, resulting in inaccurate measures and potential harm for the

233 young. From day 3 to day 15, these three traits were monitored every 3 days. From day 15 to day

23478 (ca. 12 weeks), chicks were measured once a week. Body mass was recorded using a digital

235 balance to the nearest $0.1 \mathrm{~g}$. Wing and tarsus lengths were respectively measured with a ruler and 236 a calliper to the nearest $0.5 \mathrm{~mm}$ and $0.1 \mathrm{~mm}$. The sample size for the growth analysis was $7 \mathrm{CO}$,

$23711 \mathrm{~T}_{3}, 18 \mathrm{~T}_{4}$ and $21 \mathrm{~T}_{3} \mathrm{~T}_{4}$. From week 6 to week 10, we monitored cloacal gland development 
238 and foam production in 28 males. Cloacal glands were measured every other day with a calliper

239 to the nearest $0.1 \mathrm{~mm}$ as a proxy for testes development and sexual maturation (Biswas et al.,

240 2007). Foam production (by gently squeezing the cloacal gland) was assessed at the same time

241 and coded from 0 (no foam) to 3 (high production of foam), as a proxy of cloacal gland function

242 (Cheng et al., 1989a; Cheng et al., 1989b). The same observer performed all measurements. We

243 collected eggs produced by 10 -week-old females over a 6-day period and recorded their mass to

244 the nearest $0.1 \mathrm{~g}$. We collected on average 5.7 eggs $($ range $=4-7)$ per female from 28 females.

245 Monitoring of cloacal gland regression and moult

246 In Japanese quails, exposure to short photoperiod and cold temperature triggers reproductive

247 inhibition and postnuptial moulting (Tsuyoshi \& Wada, 1992). Thyroid hormones are known to

248 coordinate these two responses (see introduction). When the birds reached the age of ca. 7

249 months, we exposed birds to short photoperiod (8L:16D, i.e., light from 08.00 to 16.00 ) with a

250 12:12-h cycle of normal $\left(20^{\circ} \mathrm{C}\right)$ and low $\left(9^{\circ} \mathrm{C}\right)$ temperature (low temperature was effective from

251 18.00 to 06.00). Cloacal gland regression (as a proxy for testes regression) was monitored every

252 other day for 2 weeks with a calliper by measuring the width and length to obtain the area of the

253 gland to the nearest $0.1 \mathrm{~mm}^{2}\left(\mathrm{~N}=26\right.$ males; $4 \mathrm{CO}, 4 \mathrm{~T}_{3}, 8 \mathrm{~T}_{4}$ and $\left.12 \mathrm{~T}_{3} \mathrm{~T}_{4}\right)$. Primary moult was

254 recorded from a single wing by giving a score to each primary from 0 (old feather) to 5 (new

255 fully-grown feather) following Ginn and Melville (1983) $(\mathrm{N}=54$ males and females; $7 \mathrm{CO}, 11$

$256 \mathrm{~T}_{3}, 16 \mathrm{~T}_{4}$ and $20 \mathrm{~T}_{3} \mathrm{~T}_{4}$ ). The total score of moulting was obtained by adding the score of all

257 feathers. The sample size for the moult analysis was $7 \mathrm{CO}, 11 \mathrm{~T}_{3}, 16 \mathrm{~T}_{4}$ and $20 \mathrm{~T}_{3} \mathrm{~T}_{4}$.

258 Oxidative status biomarker analyses

259 Two blood samples were drawn, when birds were 2 weeks $(\mathrm{N}=51$ chicks) and 4 months old $(\mathrm{N}$ 
$260=49$ adults), respectively. The sample size per treatment was $7 \mathrm{CO}, 11 \mathrm{~T}_{3}, 17 \mathrm{~T}_{4}$ and $20 \mathrm{~T}_{3} \mathrm{~T}_{4}$.

$261200 \mu 1$ of blood was collected from the brachial vein in heparinized capillaries and directly

262 frozen in liquid nitrogen. Then, the samples were stored at $-80^{\circ} \mathrm{C}$ until analyses. We measured

263 various biomarkers of antioxidant status; the antioxidant glutathione ( $\mathrm{tGSH})$, the ratio of reduced

264 and oxidised glutathione (GSH:GSSG) and activity of the antioxidant enzymes glutathione

265 peroxidase (GPx), catalase (CAT) and superoxide dismutase (SOD) from the blood. Measuring

266 multiple biomarkers of oxidative and antioxidant status allows a broader understanding of the

267 mechanism, and the interpretation of the results is more reliable if multiple markers show similar

268 patterns. The GSH:GSSG ratio represents the overall oxidative state of cells and a low ratio

269 reveals oxidative stress (Hoffman, 2002; Isaksson et al., 2005; Lilley et al., 2013; Rainio et al.,

270 2013; Halliwell \& Gutteridge, 2015). GPx enzymes catalyse the glutathione cycle, whereas CAT

271 and SOD directly regulate the level of reactive oxygen species (ROS) (Ercal, Gurer-Orhan \&

272 Aykin-Burns, 2001; Halliwell \& Gutteridge, 2015). The methodology for measuring each

273 biomarker is described in detail in Rainio et al. (2015). All analyses were conducted blindly of

274 the treatment following Ruuskanen et al (2017).

275 Ethics

276 The study complied with Finnish regulation and was approved by the Finnish Animal

277 Experiment Board (ESAVI/1018/04.10.07/2016). In case of signs of harassment or disease, birds

278 were placed in quarantine and monitored daily until they had recovered. Criteria for humane

279 endpoints were defined as follow: passive behaviour, loss of appetite, loss of $30 \%$ of body

280 weight, moving abnormally, trouble breathing. If we observed no clear improvement after two

281 days, we would consult the veterinarian. A bird would be euthanised if it does not show signs of

282 improvement in the next two days, though some judgement can be applied based on the alleged 
283 cause. One male was euthanised before the end of the experiment due to severe head injury. At

284 the end of the experiment, all birds were euthanised by decapitation for collection of tissue

285 samples (not used in this study).

\section{Statistical analysis}

287 Data were analysed with the software R version 3.5.3 (R core team, 2019). In this study, two 288 different statistical approaches were used: null-hypothesis testing with Generalised Linear Mixed 289 Models (GLMMs) and Linear Mixed Models (LMMs), and multimodel inference with

290 Generalised Additive Mixed Models (GAMMs). GAMMs were used to analyse the data on body 291 and cloacal gland growth to account for its non-linear pattern (see Growth). In this analysis, we

292 preferred multimodel inference as GAMMs generate many candidate models that cannot be 293 directly compared (e.g., by the Kenward-Roger approach). Instead, candidate models were 294 ranked based on their Akaike Information Criterion (AIC) values. Models with a $\Delta$ AIC $\leq 2$ from

295 the top-ranked model were retained in the set of best models. Akaike weights of all models were 296 calculated following (Burnham \& Anderson, 2002), and evidence ratios of the top-ranked models

297 were calculated as the weight of a model divided by the weight of the null model (Burnham, 298 Anderson \& Huyvaert, 2011). To estimate the effect of the predictors, we computed the 95\% 299 confidence intervals from the best models using the nlme package (Pinheiro et al., 2018).

300 GLMMs and LMMs were fitted using the R package lme4 (Bates et al., 2015), and GAMMs

301 were fitted using the package $m g c v$ (Wood, 2017). P-values for GLMMs were obtained by

302 parametric bootstrapping with 1,000 simulations and p-values for LMMs were calculated by

303 model comparison using Kenward-Roger approximation, using the package pbkrtest in both

304 cases (Halekoh \& Højsgaard, 2014). Post-hoc Tukey analyses were conducted with the package 305 multcomp (Hothorn et al., 2008). Model residuals were checked visually for normality and 
306 homoscedasticity. Covariates and interactions were removed when non-significant $(\alpha=0.05)$.

307 Effect size calculations (Cohen's d and 95\%CI) were performed with the website

308 estimationstats.com (Ho et al., 2019) and statistical power analyses were performed using t-tests

309 for independent means with GPower (Faul et al., 2009) with the effect size values calculated.

310 When presenting and discussing our results, we use the language of statistical "clarity" rather

311 than statistical "significance" as suggested by Dushoff et al. (2019).

\section{Hatching success}

313 To analyse hatching success, each egg was given a binary score: 0 for unhatched egg and 1 for

314 hatched egg. A GLMM was fitted with a binomial error distribution (logit link) and mother

315 identity as a random intercept and the 4-level treatment as the predictor. Egg mass might affect

316 hatchability and was therefore added as a covariate in both models. The potential effect of

317 storage duration on hatchability (Reis, Gama \& Soares, 1997) was accounted for by including

318 laying order as a covariate in both models. This covariate allowed us to control for the age of the 319 egg as well.

320 Duration of embryonic period, age at embryonic mortality and early morphological traits

321 Duration of embryonic period and early morphological traits (mass and wing length at hatching,

322 and tarsus length at day 3) were modelled with separate LMMs. Treatment, sex of the individuals

323 and egg mass were included as fixed factors. Laying order was added as a covariate to account

324 for potential effects of storage duration on hatching time and on chick weight (Reis, Gama \&

325 Soares, 1997). Mother identity was included as a random intercept.

326 The data for embryonic age had a skewed distribution and residuals were not normally

327 distributed and heterogenous, which violated LMM assumptions on residual distribution. We 
328 therefore performed a simple Kruskal-Wallis test.

329 Growth

330 As growth curves typically reach an asymptote, we fitted non-linear GAMMs to these curves.

331 Growth in body mass, tarsus and wing length were analysed in separate GAMMs. Growth was

332 analysed until week 10 after hatching as all birds appeared to have reached their maximum body

333 mass and tarsus and wing length. The data are composed of repeated measurements of the same

334 individuals over time; therefore, we first corrected for temporal autocorrelation between the

335 measurements using an $\operatorname{ARMA}(1,1)$ model for the residuals (Zuur et al., 2009). Second, as

336 mothers produced several eggs, the models included nested random effects, with measured

337 individuals nested into mother identity, allowing for random intercepts. GAMMs allow

338 modelling the vertical shift of the curves (i.e., changes in intercepts) and their shape. Treatment

339 and sex were included as predictors. A smoothing function for the age of the birds was included

340 to model the changes in the growth curves, and was allowed to vary by sex or treatment only, or

341 none of these predictors. The interaction between sex and treatment was not analysed due to low

342 statistical power. Additive effect of treatment and sex was tested for the intercept but could not

343 be computed for curve shape. All combinations of the relevant predictors were tested for both

344 shape parameters (i.e., intercept and curve shape).

345 Prenatal THs may exert most of their effects in the offspring early life; this is why we

346 additionally tested hatchlings morphological traits apart from the growth curve. Likewise, we

347 also analysed separately morphological traits at adulthood (ca. 9 weeks old), as these traits may

348 condition the fitness of an individual. Because of sex differences and low sex-specific sample

349 sizes, we standardised the measures within sex and regressed the standardised responses against

350 treatment in a linear regression. 
352 Due to low sample sizes in these sex-specific responses, we could not perform robust statistical

353 analyses. We therefore present these analyses and results in the supplementary material and only

354 briefly discuss them (Figs. S6 to S9; Table S3).

355 Moult

356 Two parameters of moult were analysed in separate LMMs: the timing of moult (i.e., the moult

357 score after one week of short photoperiod), and the rate of moult (i.e., how fast birds moulted).

358 Both models included treatment and sex as fixed factors, and mother identity as a random

359 intercept. The rate of moult was tested by fitting an interaction between treatment and age. This

360 model also included the main effect of age and individual identity, nested within mother identity,

361 as a random intercept to account for repeated measures. Estimated marginal means and standard

362 errors (EMMs $\pm \mathrm{SE}$ ) were derived from the model using the package emmeans (Lenth, 2019).

363 Oxidative stress

364 A principal component analysis (PCA) was first performed on measured antioxidant markers

365 (SOD, CAT, GPx, tGSH and GST), to reduce the number of metrics for subsequent analyses.

366 The first and the second principal components (PCs) explained together $60.2 \%$ of the variance

367 (Table 1). PC1 and PC2 were then used as dependent variables in separate LMMs. LMMs

368 included the treatment, sex and age of individuals ( 2 weeks and 4 months old) as fixed factors

369 and the 2-way interactions between treatment and sex, and treatment and age. Mother and

370 individual identities, to account for repeated measures, were added as random intercepts.

371 Malondialdehyde (MDA) is a marker of oxidative damage, which is a different measure from

372 antioxidant activity, and was therefore analysed in a separate LMM using the same parameters as 
373 for $\mathrm{PC} 1$ and $\mathrm{PC} 2$, adding the batch of the assay as an additional random intercept. The marker of

374 cell oxidative status (GSH:GSSG ratio) was analysed with the same model used for PC1 and

375 PC2.

376 Results

377 Effects of prenatal THs on hatching success and age of embryo mortality

378 There was a clear effect of elevated prenatal THs on hatching success (GLMM, $p=0.03$, Fig. 1).

379 Tukey post-hoc analysis revealed that hatching success in the $\mathrm{T}_{3} \mathrm{~T}_{4}(66 \%)$ group was statistically

380 higher than in the $\mathrm{CO}$ group (32\%) (Tukey $z=2.77, \mathrm{p}=0.03)$. There was a non-significant trend

381 between the $\mathrm{T}_{4}(61 \%)$ and the $\mathrm{CO}$ groups $(z=2.37, \mathrm{p}=0.08)$. There were no clear differences in

382 hatching success between the $\mathrm{T}_{3}(48 \%)$ and the CO group $(z=1.25, \mathrm{p}=0.45)$, or between the

383 hormone treatments (all $z<1.61$, all $\mathrm{p}>0.37)$.

384 Dissection of the unhatched eggs showed that age of embryo mortality did not differ

385 between the treatments (Kruskal-Wallis $\chi^{2}=7.22, \mathrm{df}=3, \mathrm{p}=0.07$; Fig. S1). Finally, the

386 manipulation of yolk THs did not affect the duration of embryonic period (LMM, $F_{3,42.0}=0.57, \mathrm{p}$

$387=0.64$, Fig. S2). Sex of the embryo or egg mass (LMM sex, $F_{1,49.7}=2.63, \mathrm{p}=0.11 ; \mathrm{LMM}$ egg

388 mass, $\left.F_{1,19.3}=0.01, \mathrm{p}=0.92\right)$ were also not associated with the duration of the embryonic period.

389 Laying order (i.e. the effect of storage duration) was not correlated with any of the responses (all $390 \mathrm{p} \geq 0.25)$.

391 Effects of prenatal THs on growth

392 Mass at hatching was not influenced by the elevation of prenatal THs (LMM, $F_{3,35.0}=0.81, \mathrm{p}=$

393 0.50, Fig. S3). Mass at hatching was positively correlated with egg mass (LMM, Estimate \pm SE $=$

$\left.3940.72 \pm 0.10 \mathrm{~g}, F_{1,24.1}=46.9, \mathrm{p}<0.001\right)$. Although we detected no clear differences on hatchling 
395 morphological traits (body mass, wing and tarsus length) due to prenatal THs (all $\mathrm{p}>0.12$ ), the

396 calculated effect sizes (Cohen's d[95\%CI]) and achieved statistical power yielded additional

397 information regarding the potential effects of prenatal THs (Table 2). For body mass, the effect

398 sizes were low and the achieved statistical power was very low. For wing length, the effect sizes

399 were moderate and the achieved statistical power was low. For tarsus length, the effect sizes

400 were moderate to large and the achieved statistical power was low to moderate. Similarly, adult

401 morphology was not affected by the treatment (all $p>0.13$ ), but effect sizes indicate small to

402 large effects of prenatal THs (Table 2). For body mass, the effect sizes were small and the

403 achieved power was low. For wing length, the effect sizes were large and the achieved power

404 was moderate. For tarsus length, the effect sizes were small to large and the achieved power was 405 moderate to high.

406 Regarding body mass growth, the top-ranked model showed that the curve shape and the

407 intercept differ according to sex (Table 3). After 10 weeks, females had a larger body mass than

408 males (mean \pm SE females $=214.4 \pm 5.7$ g, males $=172.4 \pm 4.5$ g, Fig. 2$)$, which was supported by

409 the $95 \%$ CIs (Table 4). Based on model selection we conclude that the treatment had no effect on

410 body mass growth (Table 3).

411 For wing growth, the top-ranked model $(\Delta \mathrm{AIC} \leq 2)$ included sex in the intercept, while

412 treatment was not included in the best supported model (Table S1). The 95\% CIs (Table 3)

413 confirmed that males had a lower wing length than females (Fig. S4).

414 Concerning tarsus growth, the models within $\triangle \mathrm{AIC} \leq 2$ included no predictors for the

415 curve shape but included treatment for the intercept (Table S2). The 95\% CIs of the parameter

416 estimates from these models suggested that there was a slight negative effect of $\mathrm{T}_{3} \mathrm{~T}_{4}$ treatment

417 on tarsus growth (Table 4, Fig. S5). However, as the estimates were close to 0 (Table 4) and 
418 evidence ratios showed that the model with treatment as a predictor was only 3.5 times more

419 supported than the null model (Table S2), we conclude that the effect of THs on tarsus length is

420 likely to be very small. Likewise, the second model for tarsus length included sex as a predictor

421 for the intercept, but its $95 \%$ CIs overlapped with 0 (Table 4 ). We therefore conclude that sex

422 had no effect on tarsus growth.

\section{Effects of prenatal THs on postnuptial moult}

424 As expected, birds started to moult soon after being exposed to short photoperiod, with an 425 average increase of moult score by 6 per week $\left(\mathrm{SE}=0.2, F_{1,254.0}=827.4, \mathrm{p}<0.001\right.$, Fig. 3). The 426 first moult score (assessed one week after switching to short photoperiod) was not affected by 427 the treatment $\left(\mathrm{LMM}, F_{3,42.7}=0.36, \mathrm{p}=0.78\right)$, but was influenced by sex, with females having a 428 higher score than male $\left(\mathrm{EMMs} \pm \mathrm{SE}\right.$ : female $=21.4 \pm 1.6$, male $=7.2 \pm 1.7 ; \mathrm{LMM} F_{1,45.3}=41.9$, $429 \mathrm{p}<0.001)$. Yolk TH elevation did not affect the rate of moult (LMM interaction treatment $\times$ 430 time, $F_{3,251.0}=0.59, \mathrm{p}=0.62$, Fig. 3).

\section{Effects of prenatal THs on oxidative stress}

432 The elevation of yolk THs had no effect on PC1 or PC2 of antioxidants at either 2 weeks 433 ("chicks") or 4 months ("adults") old (LMM on PC1, $F_{3,40.3}=2.40, \mathrm{p}=0.08$; LMM on PC2, $434 F_{3,42.2}=0.92, \mathrm{p}=0.44$, treatment $\times$ age, $\left.F<0.91, \mathrm{p}>0.44\right)$. The age of the birds had a highly 435 significant effect on PC1, with chicks generally having higher antioxidant capacities (CAT, GST 436 and $\mathrm{tGSH})$ than adults $\left(\mathrm{LMM}\right.$, Estimate $\left.\pm \mathrm{SE}=-1.34 \pm 0.19, F_{1,49.2}=52.1, \mathrm{p}<0.001\right)$. All the other

437 predictors had no effect on either PC1 or PC2 (all $F<2.93$ and all p $>0.09)$.

438 The marker of oxidative damage, MDA, was affected by the elevation of yolk THs

439 (LMM, $F_{3,43.6}=3.08, \mathrm{p}=0.04$, Fig. 4). Tukey post-hoc analysis showed that the $\mathrm{T}_{4}$ group had 
440 higher MDA values than the $\mathrm{T}_{3}$ group (Estimate $\pm \mathrm{SE}=0.01 \pm 0.004$, Tukey contrast $\mathrm{p}=0.01$ ), but

441 none of the groups differed from the control (Tukey p-values $>0.19$ ). However, this result

442 became non-significant when removing the outlier in the $\mathrm{T}_{4}$ group $\left(\mathrm{LMM}, F_{3,43.1}=2.68, \mathrm{p}=\right.$

443 0.06). MDA levels were not affected by the age or the sex of individuals (LMM age, $F_{1,54.4}=$

$4440.30, \mathrm{p}=0.59 ;$ LMM sex, $\left.F_{1,42.0}=1.47, \mathrm{p}=0.23\right)$.

445 The marker of cell oxidative balance, GSH:GSSG, was not influenced by the yolk THs

446 nor by the sex of the birds (LMM treatment, $F_{3,33.0}=0.85, \mathrm{p}=0.48 ; \mathrm{LMM}$ sex, $F_{1,40.6}=0.57, \mathrm{p}=$

447 0.45). However, chicks had a higher GSH:GSSG ratio than adults (LMM, Estimate \pm SE $=$

$\left.448 \quad 0.17 \pm 0.04, F_{1,50.0}=18.3, \mathrm{p}<0.001\right)$.

449 Discussion

450 The aim of this experimental study was to investigate the potential short-term and organisational

451 effects (with long-term consequences) of maternal thyroid hormones (THs) in a precocial

452 species, the Japanese quail, by experimental elevation of THs in eggs. Our study is the first to

453 investigate the effects of yolk $\mathrm{T}_{3}$ and $\mathrm{T}_{4}$ separately, within the natural range of the study model.

454 In addition we studied both short- and long-term effects on embryonic development, growth, life

455 stage transitions and oxidative stress. We detected a positive effect of yolk THs on hatching

456 success. All other response variables studied were not clearly affected by elevated prenatal THs.

457 Effects of prenatal THs on hatching success and embryonic development

458 The overall low hatching success, and especially in the control group, forces us to interpret these

459 results with caution. In addition, we cannot exclude that our results may be partly due to

460 selective disappearance of lower quality embryos in the control group and with injected THs

461 helping lower quality chicks to hatch. This might have biased the results after hatching, but is 
462 still a relevant effect of the hormone treatment. We found that hatching success almost doubled

463 when the eggs received an injection of both $T_{4}$ and $T_{3}$, or an injection of $T_{4}$ only. Previous

464 similar studies reported comparable effects of yolk THs in rock pigeons (Hsu et al., 2017) and in

465 collared flycatchers (Hsu et al., 2019). In these studies, injections consisted of a mixture of both

$466 \mathrm{~T}_{3}$ and $\mathrm{T}_{4}$. Given that mostly $\mathrm{T}_{3}$ binds to receptors, these results suggest that embryos likely

467 express deiodinase enzymes to convert $\mathrm{T}_{4}$ to $\mathrm{T}_{3}$, and/or yolk may contain maternally derived

468 deiodinase mRNA, as injection with $\mathrm{T}_{3}$ only did not differ from control. Indeed, deiodinase

469 expression has previously been characterised in chicken embryos already $24 \mathrm{~h}$ after the onset of

470 incubation (Darras et al., 2009). An old study found that injecting $T_{4}$ close to hatching can

471 advance hatching time, which suggests that yolk THs may help embryos overcoming hurdles

472 close to hatching (Balaban \& Hill, 1971). In contrast with our study, two similar studies in

473 altricial species detected no increased hatching success due to the injection of THs (Ruuskanen et

474 al., 2016; Sarraude et al., 2020). The dissimilarities between the studies may come from inter-

475 specific differences in terms of utilisation of yolk THs by the embryos or from context-

476 dependent effects (e.g. due to other egg components). Further comparative and mechanistic

477 studies could help understanding the dynamic of yolk THs during incubation.

478 Increased yolk THs did not influence age of embryo mortality. Similar to our study,

479 Ruuskanen et al. (2016) did not find any difference in the timing of mortality in great tit

480 embryos. Conversely, the study on rock pigeons found that yolk THs increased the proportion of

481 well-developed embryos (Hsu et al., 2017). Similar to our result on hatching success, yolk TH

482 effects on embryonic development may differ in a species-specific manner.

483 Our results on hatching success may partly be attributed to yolk THs balancing the

484 negative effects of injections on embryonic survivability. Further studies may aim at 
485 understanding the contribution of THs to counteract the effect of injection. To do so, such studies

486 may use an non-invasive method to manipulate yolk THs (e.g., egg-dipping method as in Perrin

487 et al. 1995), in addition to injected controls, like in our study.

\section{Effects of prenatal THs on growth}

489 We found no apparent influence of yolk THs on growth, contrary to our expectations based on

490 the recent literature. Other comparable studies found either a positive (Hsu et al., 2019; weak

491 effect in Sarraude et al., 2020), a negative (Hsu et al., 2017) or a sex-specific effect (Ruuskanen

492 et al., 2016) of yolk THs on growth. This notable difference may be due to the captive conditions

493 experienced by the Japanese quails in our study, with unrestricted access to food and water.

494 Although the pigeon study also provided ad libitum food, parents still needed to process food

495 before feeding their nestlings in the form of crop milk, whereas precocial quails have no such

496 limitation. In addition, the Japanese quail has been domesticated for many generations, and

497 probably selected for rapid growth for economic reasons. Whole-genome sequencing in chickens

498 showed that domestication induced a strong positive selection on genes associated with growth

499 (Rubin et al., 2010). Interestingly, that study also found a strong selection for a locus associated

500 with thyroid stimulating hormone (TSH) receptor. TSH controls most of the TH production by

501 the thyroid gland (McNabb \& Darras, 2015), and this artificial selection may overshadow the

502 effects of natural variations of prenatal THs on growth. Besides, the low number of individuals

503 in the control and $\mathrm{T}_{3}$ groups ( 7 and 11 , respectively) limited the statistical power to detect

504 differences between all the treatments. Indeed, we were able to detect small to moderate negative

505 effects of yolk THs on morphological traits at hatching and in adulthood. Such negative effects,

506 although small, may still be biologically relevant. Repeating the study with a larger sample size

507 may allow us to ascertain the effects of yolk THs on growth in precocial study models. Research 
508 on the influences of prenatal THs on growth will also benefit from experimental studies on wild

509 precocial species.

510 Effects of prenatal THs on postnuptial moult

511 Short photoperiod in combination with cold temperature triggered primary moult, as expected.

512 However, we detected no effect of yolk THs on the timing or speed of moult. Thyroid hormones

513 are important in moult and feather growth (reviewed in Dawson, 2015). For example,

514 thyroidectomised birds fail to moult after being exposed to long photoperiods (Dawson, 2015).

515 In addition, thyroidectomised nestling starlings failed to grow normal adult plumage and grown

516 feathers presented an abnormal structure (Dawson et al., 1994). By removing the thyroid gland,

517 these two studies implemented extreme pharmacological protocols that differ drastically from

518 our injection of physiological doses. In addition, our experimental design, increasing $\mathrm{TH}$

519 exposure (vs decreased TH exposure in the above-mentioned studies), may have different

520 consequences. For example, there may be a threshold above which any additional hormones may

521 not affect moult.

522 Overall, our results show no support for the hypothesis of organising effect of prenatal

523 THs on life stage transitions. Yet, due to small sample sizes in sex-specific analyses (i.e., male

524 gonadal maturation and regression, and female reproductive investment), there remains a

525 relatively high uncertainty about the potential organising effects of prenatal THs. Replicate

526 studies with larger samples sizes and different study models will reduce this uncertainty.

527 Effects of prenatal THs on oxidative stress

528 In contrast to our predictions, elevated yolk THs did not affect oxidative status during chick or

529 adult phase. We found no changes in antioxidant activities in relation to yolk THs and no 
530 imbalance in the oxidative cell status. Nevertheless, $\mathrm{T}_{4}$ birds had a higher level of oxidative

531 damage on lipids than $T_{3}$ birds, but this was a weak effect driven by one outlier. The lack of

532 effects on chick oxidative status among the treatment groups could be explained by the absence

533 of treatment effects on growth, given that high growth rates usually result in higher oxidative

534 stress and damage (e.g. Alonso-Alvarez et al., 2007). In turn, the lack of treatment effects on

535 adult oxidative status may suggest no organisational effects of prenatal THs on adult metabolism.

536 Two recent studies in altricial species also found no influence of yolk THs on nestling oxidative

537 stress (Hsu et al., 2019; Sarraude et al., 2020), yet telomere length, a biomarker of aging was

538 affected (Stier et al., 2020). Our study shows for the first time that prenatal THs have no

539 influence on adult oxidative stress either. The previous study focused on a limited set of

540 biomarkers: one antioxidant enzyme, oxidative damage on lipids and oxidative balance. In the

541 present study, we measured 7 biomarkers, thus providing broader support to the absence of

542 effects of prenatal THs on post-natal/hatching oxidative stress.

\section{Conclusion}

544 To our knowledge, this study is the first one to experimentally investigate the consequences of

545 natural variations of maternal THs not only early but also in adult physiology and postnuptial

546 moult in any vertebrate. Furthermore, this study explored for the first time the effects of maternal

$547 \mathrm{~T}_{3}$ and $\mathrm{T}_{4}$ separately. We found no evidence for differential effects of maternal $\mathrm{T}_{4}$ and $\mathrm{T}_{3}$, while

548 an effect of $\mathrm{T}_{4}$, alone or in combination with $\mathrm{T}_{3}$, on hatching success suggests that $\mathrm{T}_{4}$ is

549 converted into $\mathrm{T}_{3}$, the biologically active form during embryonic development. Contrary to

550 similar studies on wild altricial species, we found no influence of maternal THs on growth.

551 Further research on embryos utilisation of maternal THs may help understand the differences

552 observed between precocial and altricial species. Studies in other vertebrates are urgently needed 
553 to understand the potential organising effects of maternal THs with long-term consequences. 


\section{List of symbols and abbreviations}

- CAT: catalase

- CO: control treatment

- GP: glutathione peroxidase

- $\quad$ tGSH: oxidised glutathione

- GSSG: reduced glutathione

- GST: Glutathione S-transferase

- MDA: malonaldehyde

- RMR: resting metabolic rate

- SOD: super-oxide dismutase

- $\quad \mathrm{T}_{3}$ : triiodothyronine

- $\mathrm{T}_{4}$ : thyroxine

- THs: thyroid hormones

\section{Acknowledgements}

We thank Sophie Michon for her help on setting up the parental generation. We also thank Ido

Pen for consultation and help with statistical analysis, and Esther Chang for her help throughout the writing phase. 


\section{References}

554 Ainsworth SJ, Stanley RL, Evans DJR. 2010. Developmental stages of the Japanese quail. Journal of Anatomy 216:3-15. DOI: 10.1111/j.1469-7580.2009.01173.x.

556

557

558

559

560

561

562

563

564

565

566

567

568

569

570

571

572

573

574

575

Alonso M, Goodwin C, Liao X, Page D, Refetoff S, Weiss RE. 2007. Effects of Maternal Levels of Thyroid Hormone (TH) on the Hypothalamus-Pituitary-Thyroid Set Point: Studies in TH Receptor $\beta$ Knockout Mice. Endocrinology 148:5305-5312. DOI: 10.1210/en.20070677.

Alonso-Alvarez C, Bertrand S, Faivre B, Sorci G. 2007. Increased susceptibility to oxidative damage as a cost of accelerated somatic growth in zebra finches. Functional Ecology 21:873-879. DOI: 10.1111/j.1365-2435.2007.01300.x.

Anselmo J, Scherberg NH, Dumitrescu AM, Refetoff S. 2019. Reduced Sensitivity to Thyroid Hormone as a Transgenerational Epigenetic Marker Transmitted Along the Human Male Line. Thyroid 29:778-782. DOI: 10.1089/thy.2019.0080.

Balaban M, Hill J. 1971. Effects of thyroxine level and temperature manipulations upon the hatching of chick embryos (gallus domesticus). Developmental Psychobiology 4:17-35. DOI: $10.1002 / \mathrm{dev} .420040103$.

Bates D, Mächler M, Bolker B, Walker S. 2015. Fitting Linear Mixed-Effects Models Using lme4. Journal of Statistical Software 67:1-48. DOI: 10.18637/jss.v067.i01.

Bentz AB, Becker DJ, Navara KJ. 2016. Evolutionary implications of interspecific variation in a maternal effect: a meta-analysis of yolk testosterone response to competition. Royal Society Open Science 3:160499. DOI: 10.1098/rsos.160499.

Biswas A, Ranganatha OS, Mohan J, Sastry KVH. 2007. Relationship of cloacal gland with testes, testosterone and fertility in different lines of male Japanese quail. Animal 
Reproduction Science 97:94-102. DOI: 10.1016/j.anireprosci.2005.12.012.

577 Brown, C. L., Doroshov, S. I., Nunez, J. M., Hadley, C., Vaneenennaam, J., Nishioka, R. S. and

578 Bern, H. A. (1988). Maternal triiodothyronine injections cause increases in swimbladder

579 inflation and survival rates in larval striped bass, Morone saxatilis. J. Exp. Zool. 248, $580 \quad 168-176$.

581 Brown CL, Urbinati EC, Zhang W, Brown SB, McComb-Kobza M. 2014. Maternal Thyroid and 582 Glucocorticoid Hormone Interactions in Larval Fish Development, and Their 583 Applications in Aquaculture. Reviews in Fisheries Science \& Aquaculture 22:207-220. DOI: $10.1080 / 23308249.2014 .918086$.

Burnham KP, Anderson DR. 2002. Model selection and multimodel inference: a practical information-theoretic approach. New York: Springer.

587 Burnham KP, Anderson DR, Huyvaert KP. 2011. AIC model selection and multimodel inference 588 in behavioral ecology: some background, observations, and comparisons. Behavioral 589 Ecology and Sociobiology 65:23-35. DOI: 10.1007/s00265-010-1029-6.

590 Cheng KM, Hickman AR, Nichols CR. 1989. Role of the proctodeal gland foam of male $591 \quad$ Japanese Quail in natural copulations. The Auk 106:279-285.

592 Cheng KM, McIntyre RF, Hickman AR. 1989. Proctodeal Gland Foam Enhances Competitive 593 Fertilization in Domestic Japanese Quail. The Auk 106:286-291.

594 Danforth E, Burger A. 1984. The role of thyroid hormones in the control of energy expenditure. 595 Clinics in Endocrinology and Metabolism 13:581-595. DOI: 10.1016/S0300$596 \quad 595 \times(84) 80039-0$.

597 Dardente H, Hazlerigg DG, Ebling FJP. 2014. Thyroid Hormone and Seasonal Rhythmicity. $598 \quad$ Frontiers in Endocrinology 5:19. DOI: 10.3389/fendo.2014.00019. 
599 Darras VM, Van Herck SLJ, Geysens S, Reyns GE. 2009. Involvement of thyroid hormones in $600 \quad$ chicken embryonic brain development. General and Comparative Endocrinology $601 \quad$ 163:58-62. DOI: 10.1016/j.ygcen.2008.11.014.

602 Davis PJ, Goglia F, Leonard JL. 2016. Nongenomic actions of thyroid hormone. Nature Reviews 603 Endocrinology 12:111-121. DOI: 10.1038/nrendo.2015.205.

604 Dawson A. 1993. Thyroidectomy progressively renders the reproductive system of starlings 605 (Sturnus vulgaris) unresponsive to changes in daylength. Journal of Endocrinology 606 139:51-55. DOI: 10.1677/joe.0.1390051.

607

608 609

Dawson A. 2015. Chapter 38 - Avian Molting. In: Scanes CG ed. Sturkie's Avian Physiology (Sixth Edition). San Diego: Academic Press, 907-917. DOI: 10.1016/B978-0-12-4071605.00038-5.

Dawson A, McNaughton FJ, Goldsmith AR, Degen AA. 1994. Ratite-like neoteny induced by neonatal thyroidectomy of European starlings, Sturnus vulgaris. Journal of Zoology 232:633-639. DOI: 10.1111/j.1469-7998.1994.tb04618.x.

Duarte-Guterman P, Langlois VS, Pauli BD, Trudeau VL. 2010. Expression and T3 regulation of thyroid hormone- and sex steroid-related genes during Silurana (Xenopus) tropicalis early development. General and Comparative Endocrinology 166:428-435. DOI: 10.1016/j.ygcen.2009.12.008.

Dushoff J, Kain MP, Bolker BM. 2019. I can see clearly now: Reinterpreting statistical significance. Methods in Ecology and Evolution 10:756-759. DOI: 10.1111/2041210X.13159.

von Engelhardt N, Groothuis TGG. 2011. Maternal Hormones in Avian Eggs. In: Hormones and Reproduction of Vertebrates. Elsevier, 91-127. DOI: 10.1016/B978-0-12-374929- 
623 Ercal N, Gurer-Orhan H, Aykin-Burns N. 2001. Toxic Metals and Oxidative Stress Part I:

624 Mechanisms Involved in Metal-induced Oxidative Damage. Current Topics in Medicinal 625 Chemistry 1:529-539. DOI: 10.2174/1568026013394831.

626 Faul F, Erdfelder E, Buchner A, Lang A-G. 2009. Statistical power analyses using G*Power 3.1: Tests for correlation and regression analyses. Behavior Research Methods 41:1149-1160. DOI: 10.3758/BRM.41.4.1149.

Fini JB, Mével SL, Palmier K, Darras VM, Punzon I, Richardson SJ, Clerget-Froidevaux MS, Demeneix BA. 2012. Thyroid Hormone Signaling in the Xenopus laevis Embryo Is Functional and Susceptible to Endocrine Disruption. Endocrinology 153:5068-5081. DOI: 10.1210/en.2012-1463.

633 Giesing ER, Suski CD, Warner RE, Bell AM. 2011. Female sticklebacks transfer information via eggs: effects of maternal experience with predators on offspring. Proceedings of the Royal Society B: Biological Sciences 278:1753-1759. DOI: 10.1098/rspb.2010.1819.

Ginn H, Melville D. 1983. \{Moult in birds (BTO guide)\}. Thetford: British Trust for Ornithology.

Gluckman PD, Hanson MA, Spencer HG. 2005. Predictive adaptive responses and human evolution. Trends in Ecology \& Evolution 20:527-533. DOI: 10.1016/j.tree.2005.08.001.

Groothuis TGG, von Engelhardt N. 2005. Investigating Maternal Hormones in Avian Eggs: Sciences 1046:168-180. DOI: 10.1196/annals.1343.014. tool to adjust offspring phenotype in avian species. Neuroscience \& Biobehavioral 
Reviews 29:329-352. DOI: 10.1016/j.neubiorev.2004.12.002.

646

647

648

649

650

651

652

653

654

655

656

657

658

659

660

661

662

663

664

665

666

667

Halekoh, U., Højsgaard, S. 2014. A Kenward-Roger Approximation and Parametric Bootstrap Methods for Tests in Linear Mixed Models - The $R$ Package pbkrtest. J. Stat. Softw. 59.

Halliwell B, Gutteridge JMC. 2015. Free Radicals in Biology and Medicine. Oxford University Press.

Ho J, Tumkaya T, Aryal S, Choi H, Claridge-Chang A. 2019. Moving beyond P values: data analysis with estimation graphics. Nature Methods 16:565-566. DOI: 10.1038/s41592019-0470-3.

Hoffman DJ. 2002. Role of selenium toxicity and oxidative stress in aquatic birds. Aquatic Toxicology 57:11-26. DOI: 10.1016/S0166-445X(01)00263-6.

Holsberger DR, Cooke PS. 2005. Understanding the role of thyroid hormone in Sertoli cell development: a mechanistic hypothesis. Cell and Tissue Research 322:133-140. DOI: 10.1007/s00441-005-1082-z.

Hsu B-Y, Dijkstra C, Darras VM, de Vries B, Groothuis TGG. 2017. Maternal thyroid hormones enhance hatching success but decrease nestling body mass in the rock pigeon (Columba livia). General and Comparative Endocrinology 240:174-181. DOI: 10.1016/j.ygcen.2016.10.011.

Hsu B-Y, Doligez B, Gustafsson L, Ruuskanen S. 2019. Transient growth-enhancing effects of elevated maternal thyroid hormones at no apparent oxidative cost during early postnatal period. Journal of Avian Biology. DOI: 10.1111/jav.01919.

Isaksson C, Örnborg J, Stephensen E, Andersson S. 2005. Plasma Glutathione and Carotenoid Coloration as Potential Biomarkers of Environmental Stress in Great Tits. EcoHealth 2:138-146. DOI: $10.1007 / \mathrm{s} 10393-005-3869-5$. 
668 Jimeno B, Hau M, Gómez-Díaz E, Verhulst S. 2019. Developmental conditions modulate DNA 669 methylation at the glucocorticoid receptor gene with cascading effects on expression and 670 corticosterone levels in zebra finches. Scientific Reports 9:15869. DOI: 10.1038/s41598671 019-52203-8.

672 Keshavarz K, Quimby FW. 2002. An Investigation of Different Molting Techniques with an 673 Emphasis on Animal Welfare. The Journal of Applied Poultry Research 11:54-67. DOI: 10.1093/japr/11.1.54.

675

676

Kikuyama S, Kawamura K, Tanaka S, Yamamoto K. 1993. Aspects of Amphibian Metamorphosis: Hormonal Control. In: International Review of Cytology. Elsevier, 105148. DOI: $10.1016 / \mathrm{S} 0074-7696(08) 60426-\mathrm{X}$.

Korevaar TIM, Muetzel R, Medici M, Chaker L, Jaddoe VWV, de Rijke YB, Steegers EAP, Visser TJ, White T, Tiemeier H, Peeters RP. 2016. Association of maternal thyroid function during early pregnancy with offspring IQ and brain morphology in childhood: a population-based prospective cohort study. The Lancet Diabetes \& Endocrinology 4:3543. DOI: $10.1016 / \mathrm{S} 2213-8587(15) 00327-7$.

Krassas GE, Poppe K, Glinoer D. 2010. Thyroid Function and Human Reproductive Health. Endocrine Reviews 31:702-755. DOI: 10.1210/er.2009-0041.

Lenth R. 2019. emmeans: Estimated Marginal Means, aka Least-Squares Means. R package version 1.3.2.

Lilley TM, Ruokolainen L, Meierjohann A, Kanerva M, Stauffer J, Laine VN, Atosuo J, Lilius E-M, Nikinmaa M. 2013. Resistance to oxidative damage but not immunosuppression by organic tin compounds in natural populations of Daubenton's bats (Myotis daubentonii). Comparative Biochemistry and Physiology Part C: Toxicology \& Pharmacology 
157:298-305. DOI: 10.1016/j.cbpc.2013.01.003.

692

693

694

695

696

697

698

699

700

701

702

703

704

705

706

707

708

709

710

711

712

713

Marshall DJ, Uller T. 2007. When is a maternal effect adaptive? Oikos 116:1957-1963. DOI: 10.1111/j.2007.0030-1299.16203.x.

McNabb FMA. 2007. The Hypothalamic-Pituitary-Thyroid (HPT) Axis in Birds and Its Role in Bird Development and Reproduction. Critical Reviews in Toxicology 37:163-193.

McNabb FMA, Blackman JR, Cherry JA. 1985. The effects of different maternal dietary iodine concentrations on Japanese quail I. Thyroid status of hens. Domestic Animal Endocrinology 2:25-34. DOI: 10.1016/0739-7240(85)90023-2.

McNabb FMA, Darras VM. 2015. Thyroids. In: Sturkie’s Avian Physiology (Sixth Edition). London: Elsevier, 535-547. DOI: 10.1016/B978-0-12-407160-5.00024-5.

McNabb FMA, Dicken SG, Cherry JA. 1985. The effects of different maternal dietary iodine concentrations on Japanese quail II. Thyroid function in embryos and hatchlings. Domestic Animal Endocrinology 2:35-42. DOI: 10.1016/0739-7240(85)90024-4.

McNabb FMA, Scanes CG, Zeman M. 1998. Endocrine control of development. In: Avian Growth and Development: Evolution Within the Altricial-precocial Spectrum. New York: Starcj, J.M., Ricklefs, R.E., 174-202.

Medici M, Timmermans S, Visser W, de Muinck Keizer-Schrama SMPF, Jaddoe VWW, Hofman A, Hooijkaas H, de Rijke YB, Tiemeier H, Bongers-Schokking JJ, Visser TJ, Peeters RP, Steegers EAP. 2013. Maternal Thyroid Hormone Parameters during Early Pregnancy and Birth Weight: The Generation R Study. The Journal of Clinical Endocrinology \& Metabolism 98:59-66. DOI: 10.1210/jc.2012-2420.

Mommer BC, Bell AM. 2013. A test of maternal programming of offspring stress response to predation risk in threespine sticklebacks. Physiology \& Behavior 122:222-227. DOI: 
10.1016/j.physbeh.2013.04.004.

715 Mommer BC, Bell AM. 2014. Maternal Experience with Predation Risk Influences Genome-

716 Wide Embryonic Gene Expression in Threespined Sticklebacks (Gasterosteus aculeatus).

717 PLoS ONE 9:e98564. DOI: 10.1371/journal.pone.0098564.

718 Morreale de Escobar G, Obregon M, Escobar del Rey F. 2004. Role of thyroid hormone during

719 early brain development. European Journal of Endocrinology:U25-U37. DOI:

720 10.1530/eje.0.151u025.

721 Morreale De Escobar G, Pastor R, Obregón MJ, Escobar Del Rey F. 1985. Effects of maternal

722 hypothyroidism on the weight and thyroid hormone content of rat embryonic tissues,

723 before and after onset of fetal thyroid function. Endocrinology 117:1890-1900.

724 Mousseau TA, Fox CW. 1998. Maternal Effects As Adaptations. New York: Oxford University 725 Press.

726 Okuliarova M, Groothuis TGG, Škrobánek P, Zeman M. 2011. Experimental Evidence for

727 Genetic Heritability of Maternal Hormone Transfer to Offspring. The American Naturalist 177:824-834. DOI: 10.1086/659996.

729 Okuliarová M, Škrobánek P, Zeman M. 2007. Effect of Increasing Yolk Testosterone Levels on Early Behaviour in Japanese Quail Hatchlings. Acta Veterinaria Brno 76:325-331. DOI:

Perrin FMR, Stacey S, Burgess AMC, Mittwoch U. 1995. A quantitative investigation of gonadal feminization by diethylstilboestrol of genetically male embryos of the quail Coturnix coturnix japonica. Reproduction 103:223-226. DOI: 10.1530/jrf.0.1030223.

735 Pfannkuche KA, Gahr M, Weites IM, Riedstra B, Wolf C, Groothuis TGG. 2011. Examining a pathway for hormone mediated maternal effects - Yolk testosterone affects androgen 
737

738

739

740

741

742

743

744

745

746

747

748

749

750

751

752

753

754

755

756

757

758

759

receptor expression and endogenous testosterone production in young chicks (Gallus gallus domesticus). General and Comparative Endocrinology 172:487-493. DOI: 10.1016/j.ygcen.2011.04.014.

Pick JL, Ebneter C, Hutter P, Tschirren B. 2016. Disentangling Genetic and Prenatal Maternal Effects on Offspring Size and Survival. The American Naturalist 188:628-639. DOI: 10.1086/688918.

Pinheiro JC, Bates DM, Sarkar D, R Core Team. 2018. nlme: Linear and Nonlinear Mixed Effects Models. R package version 3.1-137.

Podmokła E, Drobniak SM, Rutkowska J. 2018. Chicken or egg? Outcomes of experimental manipulations of maternally transmitted hormones depend on administration method - a meta-analysis: Maternal hormones and manipulation methods. Biological Reviews 93:1499-1517. DOI: 10.1111/brv.12406.

Prati M, Calvo R, Morreale G, Morreale de Escobar G. 1992. L-thyroxine and 3,5,3'triiodothyronine concentrations in the chicken egg and in the embryo before and after the onset of thyroid function. Endocrinology 130:2651-2659. DOI: 10.1210/endo.130.5.1572286.

Raine JC, Cameron C, Vijayan MM, Lamarre J, Leatherland JF. 2004. The effect of elevated oocyte triiodothyronine content on development of rainbow trout embryos and expression of mRNA encoding for thyroid hormone receptors. Journal of Fish Biology 65:206-226. DOI: $10.1111 / \mathrm{j} .0022-1112.2004 .00445 . x$.

Rainio MJ, Eeva T, Lilley T, Stauffer J, Ruuskanen S. 2015. Effects of early-life lead exposure on oxidative status and phagocytosis activity in great tits (Parus major). Comparative Biochemistry and Physiology Part C: Toxicology \& Pharmacology 167:24-34. DOI: 
10.1016/j.cbpc.2014.08.004.

761

762

763

764

765

766

767

768

769

770

771

772

773

774

775

776

777

778

779

780

781

782

Rainio MJ, Kanerva M, Salminen J-P, Nikinmaa M, Eeva T. 2013. Oxidative status in nestlings of three small passerine species exposed to metal pollution. Science of The Total Environment 454-455:466-473. DOI: 10.1016/j.scitotenv.2013.03.033.

Reis LH, Gama L, Soares M. 1997. Effects of short storage conditions and broiler breeder age on hatchability, hatching time, and chick weights. Poultry Science 76:1459-1466. DOI: $10.1093 / \mathrm{ps} / 76.11 .1459$.

Rubin C-J, Zody MC, Eriksson J, Meadows JRS, Sherwood E, Webster MT, Jiang L, Ingman M, Sharpe T, Ka S, Hallböök F, Besnier F, Carlborg Ö, Bed'hom B, Tixier-Boichard M, Jensen P, Siegel P, Lindblad-Toh K, Andersson L. 2010. Whole-genome resequencing reveals loci under selection during chicken domestication. Nature 464:587-591. DOI: 10.1038 /nature 08832 .

Ruuskanen S, Darras VM, Visser ME, Groothuis TGG. 2016. Effects of experimentally manipulated yolk thyroid hormone levels on offspring development in a wild bird species. Hormones and Behavior 81:38-44. DOI: 10.1016/j.yhbeh.2016.03.006.

Ruuskanen S, Hsu B-Y. 2018. Maternal Thyroid Hormones: An Unexplored Mechanism Underlying Maternal Effects in an Ecological Framework. Physiological and Biochemical Zoology 91:904-916. DOI: 10.1086/697380.

Ruuskanen S, Morosinotto C, Thomson RL, Ratnayake CP, Korpimäki E. 2017. Food supplementation, but not predation risk, alters female antioxidant status during breeding. Behavioral Ecology and Sociobiology 71:69. DOI: 10.1007/s00265-017-2299-z.

Sarraude T, Hsu B-Y, Groothuis T, Ruuskanen S. 2020. Manipulation of prenatal thyroid hormones does not affect growth or physiology in nestling pied flycatchers. Physiological 
and Biochemical Zoology, in press.

784 Sekimoto K, Imai K, Suzuki M, Takikawa H, Hoshino N, Totsuka K. 1987. Thyroxine-Induced

785 Molting and Gonadal Function of Laying Hens. Poultry Science 66:752-756. DOI:

$786 \quad 10.3382 /$ ps.0660752.

787 Srichomkwun P, Anselmo J, Liao X-H, Hönes GS, Moeller LC, Alonso-Sampedro M, Weiss RE,

788 Dumitrescu AM, Refetoff S. 2017. Fetal Exposure to High Maternal Thyroid Hormone

789 Levels Causes Central Resistance to Thyroid Hormone in Adult Humans and Mice. The

$790 \quad$ Journal of Clinical Endocrinology \& Metabolism 102:3234-3240. DOI: 10.1210/jc.2017-

$791 \quad 00019$.

792 Stier A, Hsu B-Y, Marciau C, Doligez B, Gustafsson L, Bize P, Ruuskanen S. 2020. Born to be

793 young: prenatal thyroid hormones increase early-life telomere length. bioRxiv. DOI:

794 10.1101/2020.05.07.083667.

Stier A, Metcalfe NB, Monaghan P. 2019. Ageing before birth: pace and stability of prenatal 796 growth affect telomere dynamics. bioRxiv:809087. DOI: 10.1101/809087.

Tsuyoshi H, Wada M. 1992. Termination of LH secretion in Japanese quail due to high- and low-temperature cycles and short daily photoperiods. General and Comparative Endocrinology 85:424-429. DOI: 10.1016/0016-6480(92)90087-Z.

800 Van Herck SLJ, Delbaere J, Bourgeois NMA, McAllan BM, Richardson SJ, Darras VM. 2015. 801 Expression of thyroid hormone transporters and deiodinases at the brain barriers in the embryonic chicken: Insights into the regulation of thyroid hormone availability during neurodevelopment. General and Comparative Endocrinology 214:30-39. DOI: 10.1016/j.ygcen.2015.02.021.

Wada H. 2008. Glucocorticoids: Mediators of vertebrate ontogenetic transitions. General and 
807 Walpita CN, Van der Geyten S, Rurangwa E, Darras VM. 2007. The effect of 3,5,3'-

808 triiodothyronine supplementation on zebrafish (Danio rerio) embryonic development and

809 expression of iodothyronine deiodinases and thyroid hormone receptors. General and

810 Comparative Endocrinology 152:206-214. DOI: 10.1016/j.ygcen.2007.02.020.

811 Watanabe Y, Grommen SVH, De Groef B. 2016. Corticotropin-releasing hormone: Mediator of

812 vertebrate life stage transitions? General and Comparative Endocrinology 228:60-68.

813 DOI: 10.1016/j.ygcen.2016.02.012.

814 Wilson CM, McNabb FMA. 1997. Maternal Thyroid Hormones in Japanese Quail Eggs and

815 Their Influence on Embryonic Development. General and Comparative Endocrinology

$816 \quad$ 107:153-165. DOI: 10.1006/gcen.1997.6906.

817 Wood SN. 2017.Generalized Additive Models: An Introduction with R, Second Edition.

818 Available at https://www.crcpress.com/Generalized-Additive-Models-An-Introduction-

819 with-R-Second-Edition/Wood/p/book/9781498728331 (accessed November 8, 2018).

820 Zuur AF, Ieno EN, Walker NJ, Savaliev AA, Smith GM. 2009. Mixed effects models and

$821 \quad$ extensions in ecology with R. New York, NY: Springer.

823

824

825

826 


\section{Table 1 (on next page)}

Loadings of the different antioxidant biomarkers on the principal components 1 and 2 . 


\begin{tabular}{lll}
\hline Factor loadings & PC1 (34.0\%) & PC2 (26.2\%) \\
\hline CAT & -0.49 & 0.14 \\
SOD & 0.20 & -0.71 \\
GST & -0.65 & -0.10 \\
GP & 0.04 & -0.63 \\
tGSH & -0.60 & -0.26 \\
\hline
\end{tabular}

1 


\section{Table 2 (on next page)}

Cohen's d, 95\% Cls and achieved statistical power for post-hatching and adult morphological measures (body mass, wing and tarsus length).

95\% Cls were calculated by bootstrap resampling with 5,000 resamples. $\mathrm{CO}=$ control, $\mathrm{T}_{4}$

(thyroxine) $=$ injection of $T_{4}, T_{3}$ (triiodothyronine $)=$ injection of $T_{3}, T_{3} T_{4}=$ injection of $T_{3}$ and $T_{4 .}$ 


\begin{tabular}{|c|c|c|c|c|c|c|}
\hline & Hatchlings & & & Adults & & \\
\hline Contrast & Cohen's d & $95 \% \mathrm{CI}$ & $\begin{array}{l}\text { Statistical } \\
\text { power }(1-\beta)\end{array}$ & Cohen's d & $95 \% \mathrm{CI}$ & $\begin{array}{l}\text { Statistical } \\
\text { power }(1-\beta)\end{array}$ \\
\hline \multicolumn{7}{|c|}{ Body mass } \\
\hline CO-T3 & 0.22 & $-0.70 ; 1.09$ & 0.13 & -0.01 & $-1.23 ; 1.05$ & 0.05 \\
\hline CO-T4 & 0.17 & $-0.79 ; 1.11$ & 0.11 & -0.46 & $-1.54 ; 0.57$ & 0.26 \\
\hline CO-T3T4 & 0.06 & $-1.03 ; 1.05$ & 0.07 & -0.48 & $-1.61 ; 0.48$ & 0.28 \\
\hline T3-T4 & -0.09 & $-0.81 ; 0.66$ & 0.08 & -0.51 & $-1.32 ; 0.22$ & 0.36 \\
\hline T3-T3T4 & -0.24 & $-1.0 ; 0.52$ & 0.17 & -0.53 & $-1.28 ; 0.19$ & 0.40 \\
\hline T4-T3T4 & -0.16 & $-0.80 ; 0.49$ & 0.13 & -0.01 & $-0.66 ; 0.65$ & 0.05 \\
\hline \multicolumn{7}{|c|}{ Wing length } \\
\hline CO-T3 & -0.41 & $-1.33 ; 0.36$ & 0.23 & -1.07 & $-2.09 ; 0.36$ & 0.67 \\
\hline CO-T4 & -0.79 & $-1.62 ; 0.10$ & 0.57 & -0.72 & $-1.52 ; 0.20$ & 0.47 \\
\hline CO-T3T4 & -0.56 & $-1.31 ; 0.13$ & 0.37 & -0.81 & $-1.52 ; 0.11$ & 0.56 \\
\hline T3-T4 & -0.41 & $-1.09 ; 0.31$ & 0.31 & 0.12 & $-0.54 ; 0.91$ & 0.09 \\
\hline T3-T3T4 & -0.20 & $-0.80 ; 0.54$ & 0.14 & 0.09 & $-0.49 ; 0.91$ & 0.08 \\
\hline T4-T3T4 & 0.19 & $-0.44 ; 0.86$ & 0.15 & -0.03 & $-0.67 ; 0.62$ & 0.06 \\
\hline \multicolumn{7}{|c|}{ Tarsus length } \\
\hline CO-T3 & -0.58 & $-1.29 ; 0.33$ & 0.33 & -0.10 & $-1.25 ; 1.08$ & 0.07 \\
\hline CO-T4 & -0.88 & $-1.93 ; 0.08$ & 0.61 & -0.67 & $-1.59 ; 0.31$ & 0.43 \\
\hline CO-T3T4 & -0.92 & $-2.02 ; 0.06$ & 0.68 & -0.78 & $-1.73 ; 0.09$ & 0.54 \\
\hline T3-T4 & 0.01 & $-0.91 ; 1.02$ & 0.05 & -0.68 & $-1.41 ; 0.08$ & 0.53 \\
\hline T3-T3T4 & 0.05 & $-0.91 ; 1.07$ & 0.06 & -0.79 & $-1.44 ;-0.11$ & 0.67 \\
\hline T4-T3T4 & 0.06 & $-0.69 ; 0.79$ & 0.07 & -0.11 & $-0.73 ; 0.54$ & 0.10 \\
\hline
\end{tabular}




\section{Table 3 (on next page)}

Results of the Generalised Additive Mixed Models (GAMMs) on body mass growth, with sex and treatment fitted either as intercept, curve shape or both (all combinations tested).

A total of 12 GAMMs were fitted and ranked based on their AIC, from the lowest to the highest. Weight: Akaike's weight. 


\begin{tabular}{rllrrc}
\hline Model & Intercept & Curve shape & $\Delta$ AIC & df & $\begin{array}{l}\text { Weigh } \\
\mathbf{t}\end{array}$ \\
\hline 1 & Sex & Sex & 0.0 & 11 & 0.8430 \\
8 & Treatment + sex & Sex & 3.5 & 14 & 0.1497 \\
3 & - & Sex & 9.9 & 10 & 0.0061 \\
2 & Treatment & Sex & 13.2 & 13 & 0.0012 \\
11 & Sex & - & 77.6 & 9 & $<0.001$ \\
9 & Treatment + sex & - & 81.6 & 12 & $<0.001$ \\
12 & - & - & 91.2 & 8 & $<0.001$ \\
10 & Treatment & - & 95.0 & 11 & $<0.001$ \\
5 & Sex & Treatment & 147.9 & 15 & $<0.001$ \\
7 & Treatment + sex & Treatment & 151.7 & 18 & $<0.001$ \\
6 & - & Treatment & 161.2 & 14 & $<0.001$ \\
4 & Treatment & Treatment & 165.5 & 17 & $<0.001$ \\
\hline
\end{tabular}

1 


\section{Table 4 (on next page)}

95\% confidence intervals of the predictors in the top-ranked models according to AIC values (see Tables $2, \mathrm{~S} 1$ and S2).

Predictors in bold have confidence intervals that do not overlap with 0 . For the intercept, the reference groups are female and $\mathrm{CO}$ for the predictors sex and treatment, respectively. 


\begin{tabular}{|c|c|c|c|c|}
\hline $\begin{array}{l}\text { Curve } \\
\text { parameter }\end{array}$ & Predictors & Lower limit & Estimate & Upper limit \\
\hline \multicolumn{5}{|c|}{ (A)Body mass (Model 1) } \\
\hline Intercept & $\operatorname{Sex}(M)$ & -19.7 & -12.6 & -5.5 \\
\hline Curve shape & $\operatorname{Sex}(F)$ & 9.9 & 20.0 & 30.0 \\
\hline Curve shape & Sex $(M)$ & 14.3 & 24.5 & 34.7 \\
\hline \multicolumn{5}{|c|}{ (B) Wing length (Model 11) } \\
\hline Intercept & $\operatorname{Sex}(M)$ & -2.3 & -1.2 & -0.1 \\
\hline Curve shape & Age & 26.4 & 28.7 & 31.0 \\
\hline \multicolumn{5}{|c|}{ (C) Tarsus length (Model 10) } \\
\hline Intercept & Treatment $\left(\mathrm{T}_{3}\right)$ & -0.8 & 0.02 & 0.8 \\
\hline Intercept & Treatment $\left(\mathbf{T}_{3} \mathbf{T}_{4}\right)$ & -1.5 & -0.8 & -0.1 \\
\hline Intercept & Treatment $\left(\mathrm{T}_{4}\right)$ & -1.3 & -0.6 & 0.2 \\
\hline Curve shape & Age & 10.5 & 11.1 & 11.8 \\
\hline \multicolumn{5}{|c|}{ Tarsus length (Model 9) } \\
\hline Intercept & Treatment $\left(\mathrm{T}_{3}\right)$ & -0.9 & -0.07 & 0.7 \\
\hline Intercept & Treatment $\left(\mathbf{T}_{3} \mathbf{T}_{4}\right)$ & -1.5 & -0.8 & -0.1 \\
\hline Intercept & Treatment $\left(\mathrm{T}_{4}\right)$ & -1.4 & -0.6 & 0.1 \\
\hline Intercept & $\operatorname{Sex}(\mathrm{M})$ & -0.8 & -0.3 & 0.3 \\
\hline Curve shape & Age & 10.5 & 11.1 & 11.7 \\
\hline
\end{tabular}




\section{Figure 1}

Percentage of hatching success according to yolk TH manipulation treatments.

$N=40 \mathrm{CO}, 39 \mathrm{~T}_{3}, 39 \mathrm{~T}_{4}$ and $40 \mathrm{~T}_{3} \mathrm{~T}_{4} . \mathrm{CO}=$ control, $\mathrm{T}_{4}$ (thyroxine) = injection of $\mathrm{T}_{4}, \mathrm{~T}_{3}$ (triiodothyronine) $=$ injection of $T_{3}, T_{3} T_{4}=$ injection of $T_{3}$ and $T_{4}$.

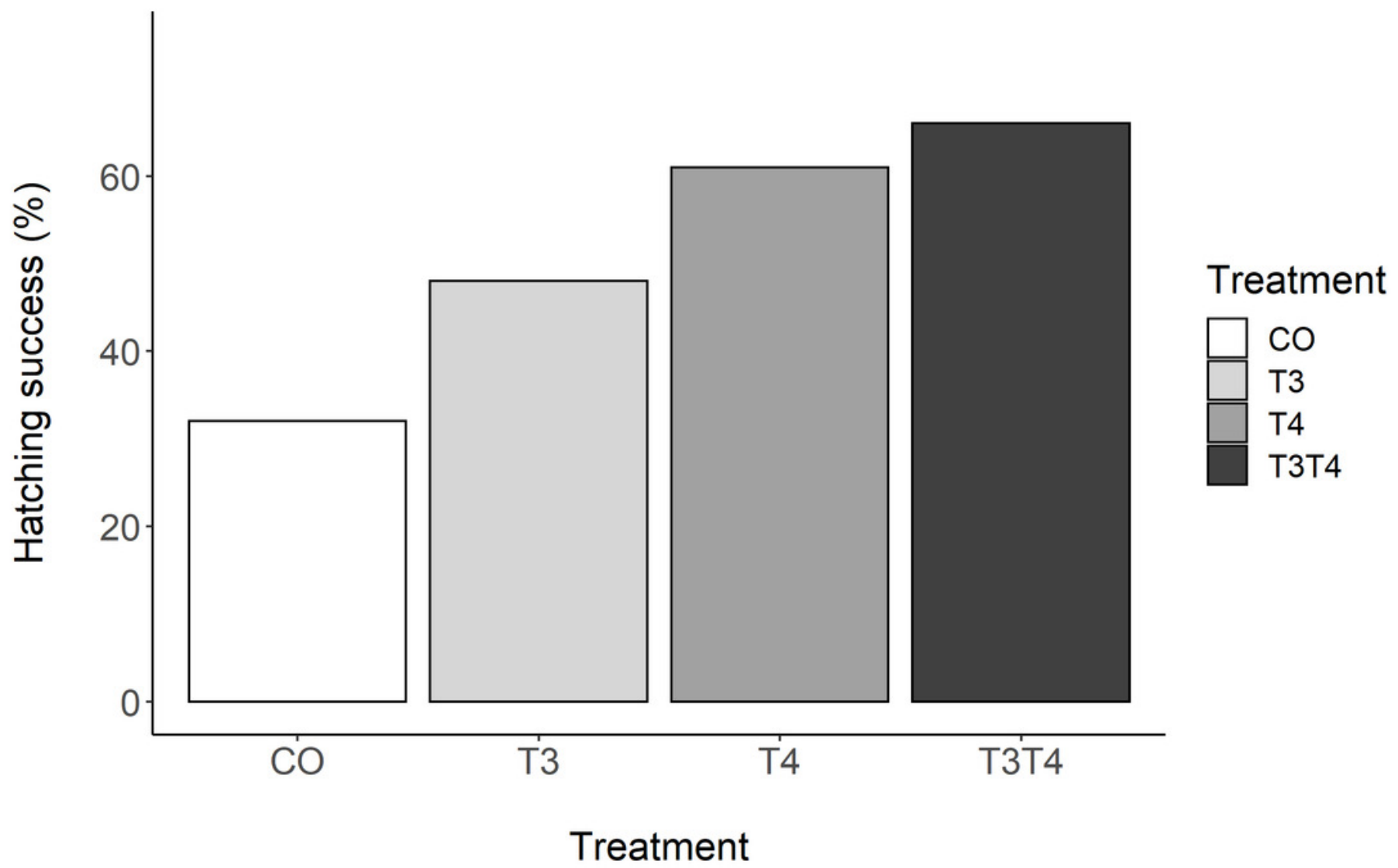


Figure 2

Growth curves in body mass of Japanese quails hatching from eggs treated with either $\mathrm{T}_{3}, \mathrm{~T}_{4}$, a combination of both hormones, or a control solution.

See Fig. 1 for a description of the treatments. Each line represents an individual bird, while thick coloured lines represent mean values. A: Growth curve according to yolk TH manipulation. $\mathrm{N}=7 \mathrm{CO}, 11 \mathrm{~T}_{3}, 18 \mathrm{~T}_{4}$ and $21 \mathrm{~T}_{3} \mathrm{~T}_{4}$. $\mathrm{B}$ : Growth curve according to sex. $\mathrm{N}=29$ females and 28 males.

A

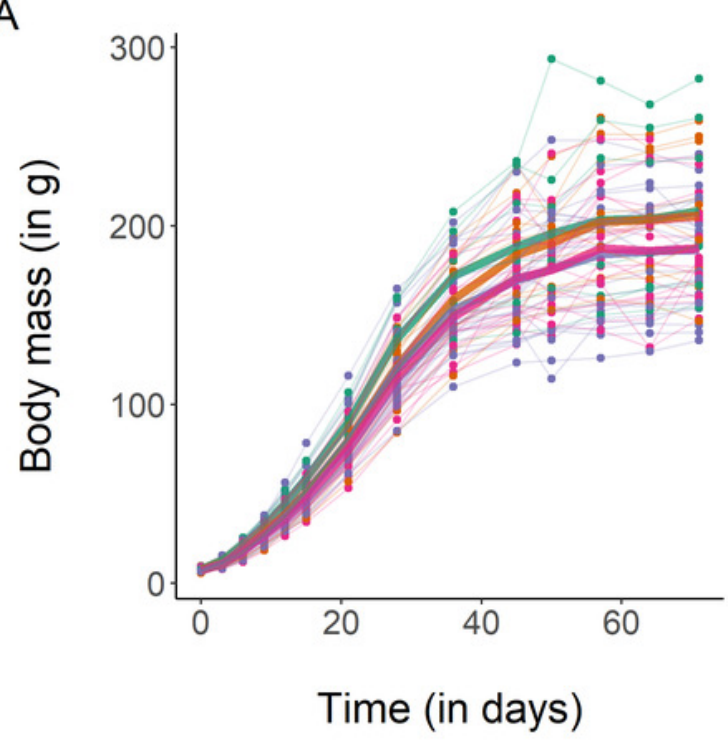

B

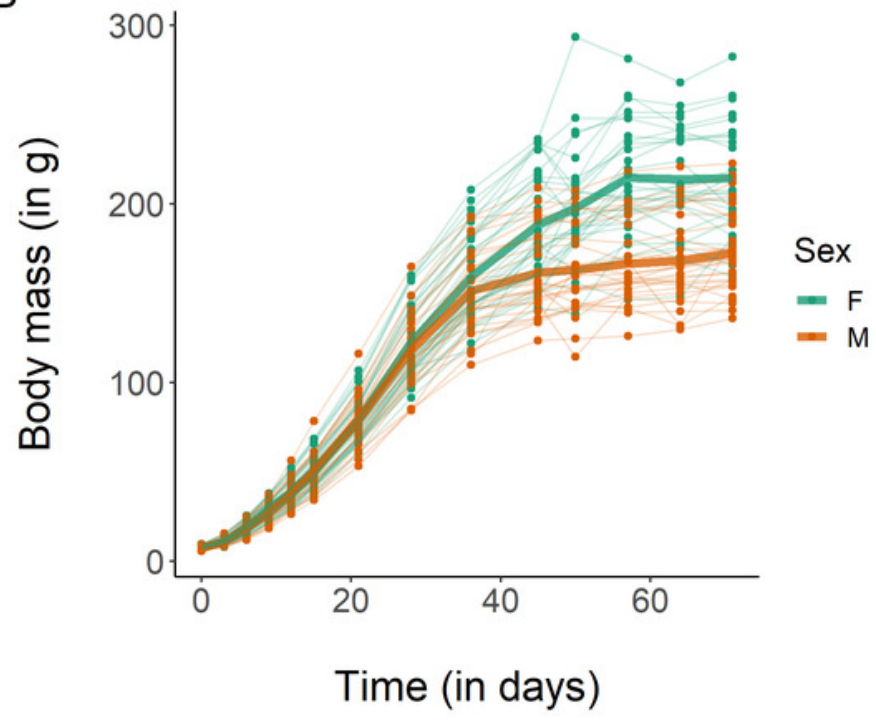


Figure 3

Primary moult score in 7-month old Japanese quails according to yolk TH manipulation treatments.

$N=7 \mathrm{CO}, 11 \mathrm{~T}_{3}, 16 \mathrm{~T}_{4}$ and $20 \mathrm{~T}_{3} \mathrm{~T}_{4}$. See Fig. 1 for a description of the treatments. Measures were taken once a week after switching from long photoperiod (16L:8D) to short photoperiod (8L:16D, switch $=$ time point 0 on $x$-axis). Each line represents an individual bird, while thick coloured lines represent group mean values.

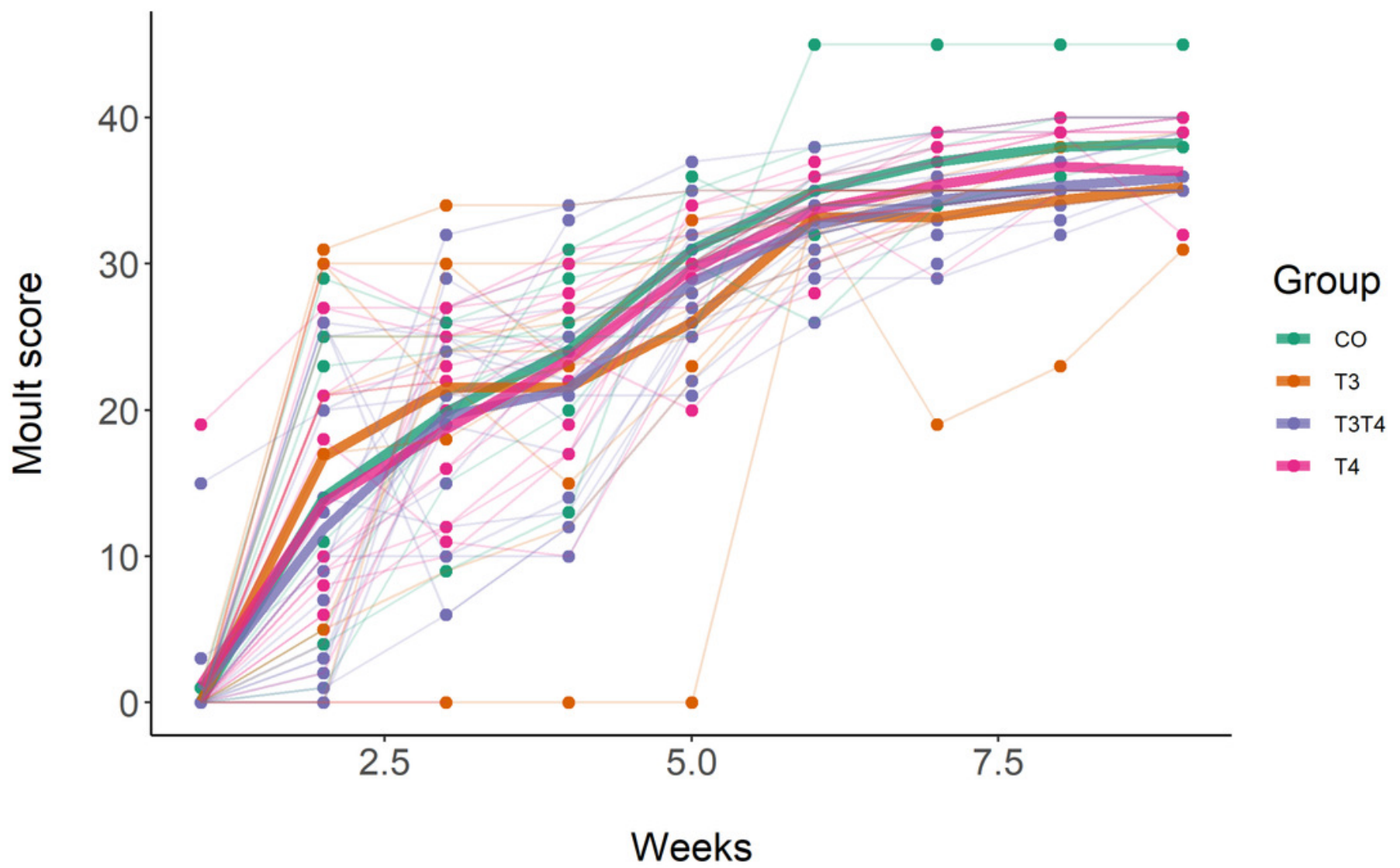


Figure 4

MDA concentration according to yolk TH manipulation treatments.

Samples from two ages pooled: $\mathrm{N}=7 \mathrm{CO}, 11 \mathrm{~T}_{3}, 17 \mathrm{~T}_{4}$ and $20 \mathrm{~T}_{3} \mathrm{~T}_{4}$. See Fig. 1 for a description of the treatments. Boxplots show median and quartiles.

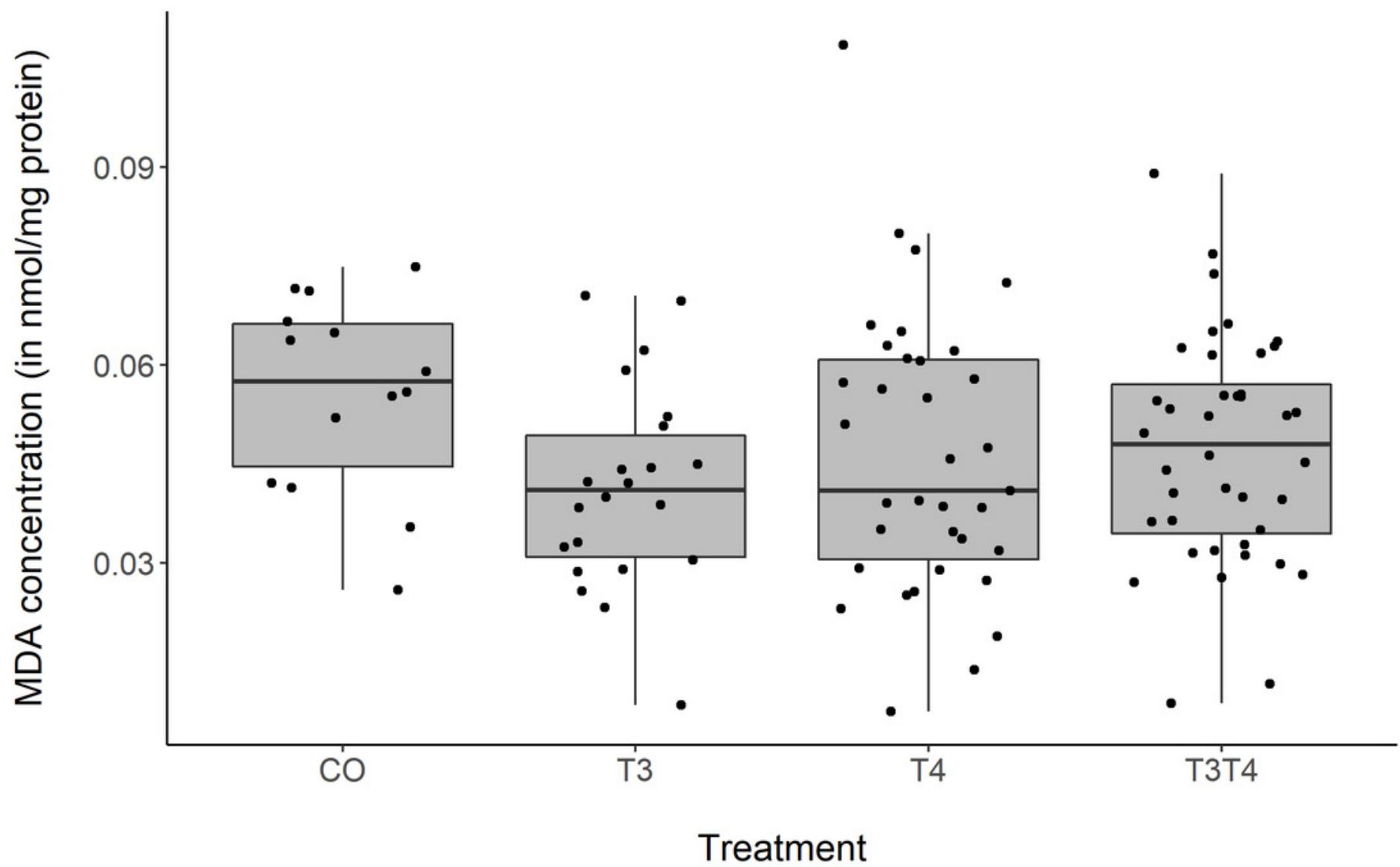

